\title{
Bland Embolization
}

National Cancer Institute

\section{Source}

National Cancer Institute. Bland Embolization. NCI Thesaurus. Code C91829.

Non-chemotherapeutic embolization involving the injection of small particles through a catheter in the hepatic artery. It is performed to block the blood supply to liver cancer. 